Anales de Literatura Hispanoamericana

ISSN-e: 1988-2351

\title{
Luis Mizón: una experiencia del exilio literario en París
}

\author{
Ximena Figueroa Flores ${ }^{1}$ y Felipe González Alfonso ${ }^{2}$
}

Resumen. Luego de su exilio en 1974, el poeta chileno Luis Mizón (Valparaíso, 1942) ha sido ampliamente reconocido en Francia, donde reside hasta la fecha. Ha publicado cerca de cincuenta libros, varios de ellos bilingües, traducidos, entre otros, por Roger Caillois y Claude Couffon, en editoriales tan prestigiosas como Gallimard y Du Seuil. Además, ha sido condecorado como Caballero de las Artes y las Letras (1990) por el Ministerio de la Cultura y la Comunicación de Francia y ha recibido el premio Benjamin Fondane (2014) para escritores francófonos. También es director de la revista Confluence poétiques fundada en 2006, y presidente de la asociación del mismo nombre.

Presentamos aquí la conferencia inédita dictada por el poeta en el Centro de Literatura Comparada de la Universidad Sorbonne, el año 2009, y que él mismo nos ha cedido junto al afiche promocional durante su última visita a Chile en el verano de 2017.

Palabras clave: Luis Mizón; exilio; París.

\section{[en] Luis Mizón: an Experience of Exit Literary in Paris}

Abstract. After his exile in 1974, the Chilean poet Luis Mizón (Valparaíso, 1942) has been widely recognized in France, where he lives to date. He has published about fifty books, several of them bilingual, translated among others by Roger Caillois and Claude Couffon, in such prestigious publishers as Gallimard and Du Seuil. He has also been awarded the Benjamin Fondane (2014) prize for French-speaking writers as a Knight of Arts and Letters (1990) by the French Ministry of Culture and Communication. He is also director of the magazine Confluence poétiques founded in 2006, and president of the association of the same name.

We present here the unpublished lecture given by the poet in the Center of Comparative Literature of the Sorbonne University, 2009, and that he has given us along with the promotional poster during his last visit to Chile in the summer of 2017.

Keywords: Luis Mizón; exile: Paris.

Cómo citar: Figueroa Flores, X. y González Alfonso, F. (2020) Luis Mizón: una experiencia del exilio literario en París, en Anales de Literatua Hispanoamericana 49, 227-240.

\section{Conferencia}

Hace unos meses, el Teatro Nacional Popular de Lyon propuso a varios escritores y poetas escribir un texto sobre el exilio. El mío lo titulé "La passerelle du Donizetti" pensando en la fotografía que ustedes ven en el afiche que anuncia esta conferencia. Hubo un "antes" y un "después" de ese momento en que me ven subiendo con mi familia a bordo del Donizetti. "Antes" es todavía el puerto de Valparaíso, Chile, mi infancia y mi adolescencia entre campo, ciudad y puerto. En el instante en que la fotografía fue tomada, mi experiencia poética engarzada en lo vivido, se separa no sin dolor de su zócalo original, se libera para hundirse en lo desconocido, en el futuro, en un "después" entonces ignorado y llamado solamente tierra de exilio o tierra de asilo. Paris, Francia, que forma parte de los mitos familiares latinoamericanos desde el siglo 
XIX, será la ciudad donde el exilio dará una forma nueva a mi obra poética. Ella se precisa a partir de ese pasaje y gracias a él; en la passerelle del Donizetti comienza mi experiencia literaria del exilio.

Agradezco al Instituto de Literatura Comparada y, en especial, a su director monsieur Pierre Brunel, la ocasión que me ha dado de reflexionar y poner en orden algunas ideas sobre este tema. Una experiencia del exilio, sea o no sea literaria, no puede ser otra cosa que una forma de autobiografía reflexionada, y les pido perdón anticipado por hablar tanto de mí mismo, lo que, como sabemos, no es signo de la mejor educación.
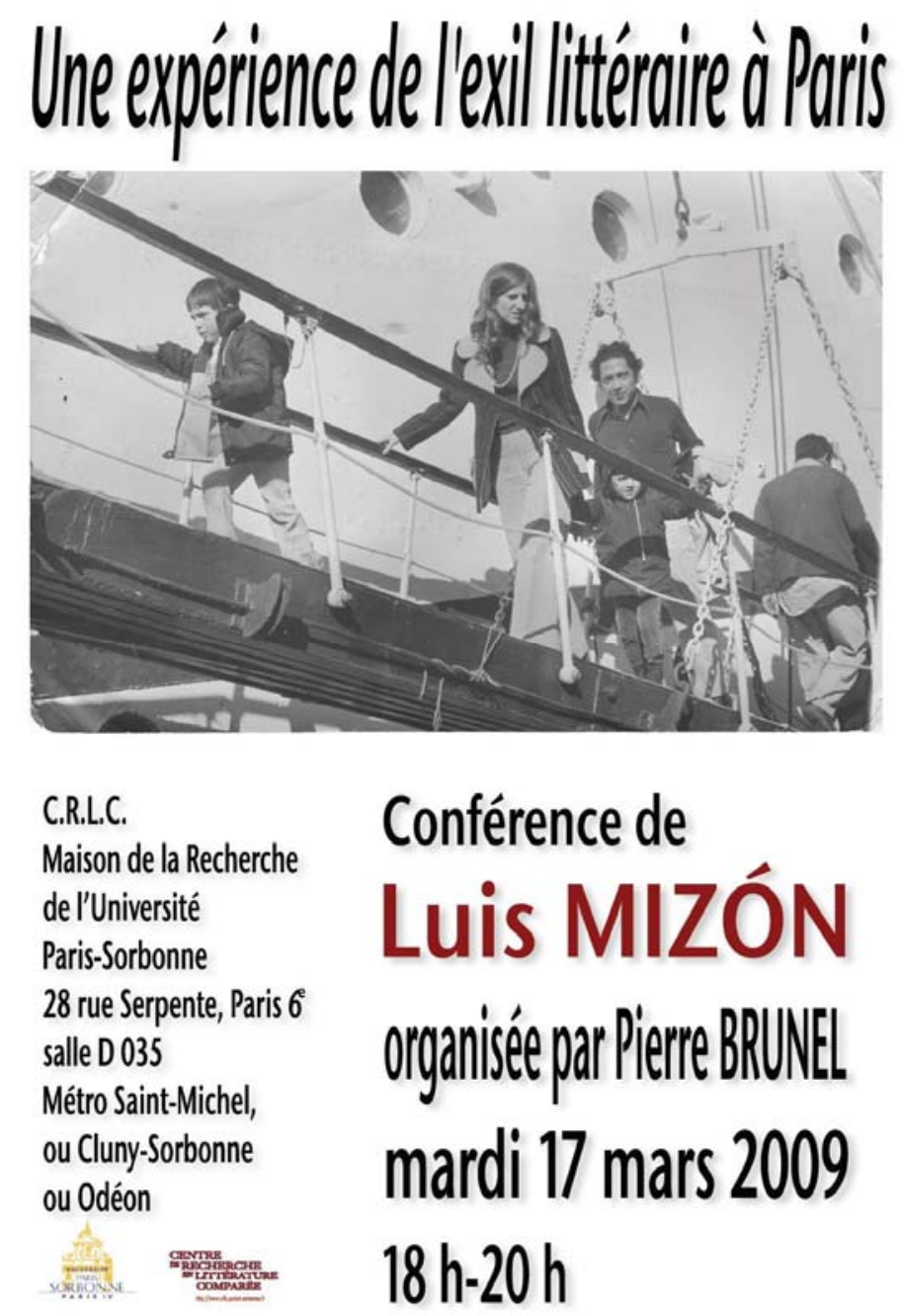

El exilio es un castigo impuesto por el poder del Estado al miembro disidente o al rebelde que se le opone. En derecho, el alejamiento impuesto como una pena a veces se llama relegación o "extrañamiento". La palabra "extrañar" significa deportar, exiliar, echar del país, alejar, rechazar, relegar, pero también el efecto que ese alejamiento produce, el echar de menos. Ese alejamiento, sin embargo, no es completamente negativo y lleva a veces a la persona relegada o extrañada a conocer cosas curiosas y sorprendentes; países y costumbres nunca vistos que forman parte de su riqueza y de su experiencia cultural. Siempre me pareció curioso que se considere una pena y un castigo vivir en una sociedad humana, por alejada que sea de alguna capital o centro urbano de mayor importancia, como si hubiera personas que nacen y viven castigadas desde su nacimiento y sin saberlo a la relegación y al extrañamiento, castigadas a vivir en su propia casa. Por su parte, la palabra "entrañable" define algo íntimo o afectuoso, verdadero o sincero. "Entrañar" es contener en germen, guardar una cosa y llevarla consigo en lo más profundo del ser. "Entrañarse" es unirse, ligarse estrechamente y de todo corazón con alguien. "Entrañar" y "extrañar" parecieran ser dos actos diametralmente opuestos y, sin embargo, ligados entre sí, como si uno contradijera al otro y se opusiera a él con la intención de anularlo. Así, por ejemplo, algo muy entrañable para los indios del Sur de Chile es la tierra donde nacen. Sus nombres señalan el lugar de sus orígenes. Y el recuerdo de esa tierra lo llevan consigo cuando parten a tierras extrañas. En forma amplia, se puede decir que un exiliado deja el país de 
origen y se radica en otro como consecuencia de una persecución política. Las razones económicas producen migraciones y no exilios.

No hay causas literarias del exilio. Cuando el poder se siente atacado por un texto, ese texto es político como la famosa epístola de Quevedo dirigida al Conde-duque de Olivares: "No he de callar, por más que con el dedo, / ya tocando la boca o ya la frente, / silencio avises o amenaces miedo". El contenido político no quita el valor literario ni lo otorga, pero la censura, en cambio, es siempre política y no literaria. Si un texto literario es malo o bueno, la consecuencia es políticamente indiferente, si es malo, pero podría ser mejor, un autor puede corregirlo o seguir el consejo de una corrección, eso no es un castigo aunque se llame corrección. Una corrección literaria es semejante a la famosa corrección fraterna de que, me parece, habla Santo Tomás, y que existe o debiera existir entre poetas amigos y es muy necesaria. Aunque no haya causas, puede haber consecuencias literarias de un exilio político y a menudo es el caso. El poema épico que funda la literatura española tiene por tema el destierro del Cid por orden del rey Alfonso VI y es un claro ejemplo de destierro político. Esa pérdida de la tierra de origen está presente en gran cantidad de obras literarias desde Ovidio hasta Saint-John Perse. Naturalmente, esto no quiere decir que detrás de cada exiliado hay un poeta.

¿Cómo la poesía llega a ocupar el primer plano en la vida de una persona? ¿De qué tipo es el reconocimiento que va a sustentar una obra? ¿Cómo vive el poeta? ¿Cómo se las arregla para realizar su obra? Es muy difícil incluso para el protagonista saber cómo y por qué en un momento determinado de su vida la poesía pasa a ocupar todo el terreno y se impone como su actividad principal. No es evidente ser poeta y a veces los alumnos de escuelas primarias se sorprenden al encontrar un espécimen de mi edad en buen estado de conservación. No es fácil vivir como poeta, la poesía exige tiempo y sacrificios, se es poeta a veces de manera más o menos clandestina. Una pregunta que a veces me han hecho los implacables niños es: Señor, ¿desde cuándo usted es poeta? Tratar de contestar a esa pregunta me dará la materia del punto de partida.

Siempre fui un gran lector, la letra en cambio me costó aprenderla, si interpreto bien algunos viejos cuadernos hinchados por los verdugones de las lágrimas. Muy pronto me acerqué al misterio que encierran los libros y asistí a sus milagros silenciosos y a sus argucias mágicas que son hacer ver cosas nunca vistas, dar sentimiento a los que se piensan secos y pensamientos a los que se creen tontos y a veces lo son y, sobre todo, encontrar gustos, olores, sabores y sensaciones olvidadas o inéditas. A partir de ese momento, se despierta en todo joven poeta algo del espíritu de los discípulos de Simón el Mago, ese contemporáneo de los apóstoles que quería comprarles a estos el secreto de hacer milagros y que afirmaba que el colmo de la sabiduría humana estaba reunido y representado por su mujer. El placer secreto y solitario de la lectura se instaló en mí con violencia. En casa de unos tíos en el campo había una obra de gruesos volúmenes llamada El tesoro de la juventud. Era una colección de obras didácticas destinadas a formar buenos ciudadanos con principios sanos, tanto políticos como religiosos y, sobre todo, patrióticos; obras típicas de fines del siglo XIX obsesionadas por la invención de las identidades nacionales y por las guerras. En ellos había a profusión poemas románticos españoles llenos de caballeros medievales, paladines y piratas, amores imposibles, romances, fábulas y pastores: desde Jovellanos y Moratín a Campoamor, de Samaniego a Heredia, de Zorrilla a Gabriel y Galán. En esa selva sonora y sentimental, salpicada de discursos varoniles y agua de rosa, destacaban Gustavo Adolfo Bécquer y Rubén Darío. Morir de amor o ser violinista me parecían destinos llenos de encanto.

Sin salir del siglo XIX, aprendí a leer los sentimientos y las emociones del internado victoriano de Dickens, viviendo en compañía de David Copperfield y de Oliverio Twist, acompañándolos en su viaje al país de los pobres. Leyendo los cuentos de Oscar Wilde descubrí que unas cuantas palabras escritas, leídas o escuchadas, podían provocar las lágrimas más ardientes. El liceo de hombres, gracias a los textos de estudio y las antologías fabulosas de Roque Esteban Scarpa, me enseñó la poesía medieval española. Conocí a Gonzalo de Berceo, el monje de Santo Domingo de Silos y sus ingenuos y amorales milagros de la virgen, el canto solemne de las estancias de don Jorge Manrique y el murmullo vegetal del Siglo de Oro donde la sombra de Cervantes me salió al camino con sus amigos poetas. El Quijote se transformó rápidamente en un compañero para toda la vida. Uno de mis grandes placeres fue hacer un curso sobre Cervantes en el Departamento de Español de la Universidad de Nancy II.

Muy buenos profesores me enseñaron que aprender de memoria un poema era un placer y no un deber. Retener el texto y poder leerlo en lo más íntimo, sentirlo pasar de una memoria ajena a la nuestra, era en realidad no solo un placer inmenso, sino también una preparación para el exilio. Así aprendí sonetos de Góngora y de Garcilaso de la Vega, y de Fray Luis de León, que se transformó en uno de mis preferidos y sobre el que hice una emisión en France Culture con la colaboración de mi amigo Michel de Certeau. Guardar unos cuantos poemas en la memoria es lo que han hecho siempre los españoles y los latinoamericanos sin por eso ser poetas. Don Quijote cita constantemente poetas bien escondidos y 
camuflados para que no los encuentren ni el cura ni el barbero, y lo mismo hicieron los conquistadores casi analfabetos de América que recordaban y citaban el romancero.

Federico García Lorca fue mi primer encuentro con la gran poesía contemporánea y mi reacción creo que fue la buena; de la admiración pasé a la imitación más o menos consciente. En esta sabia asamblea creo que se respetará esa tradición antigua de la imitación, que por otra parte sirve de antídoto a la imitación involuntaria. Un cierto control de la imitación me sirvió más tarde para desembarazarme de Neruda, de Rilke, de Lorca y de Saint-John Perse.

Pero nada de eso explica por qué me dio por escribir versos. En Chile le dicen a una persona que súbitamente cambia de carácter, ¿qué bicho lo picó que se puso así? Los antiguos hablan de esa locura divina, de ese furor que a lo mejor es lo mismo. Me picó el bicho de la poesía y me inoculó su locura en un momento preciso de mi adolescencia, en el paso a la pubertad y fue algo sorprendente para mí. Hasta recuerdo ahora mismo la escena original. Las flores azules de un arbusto en pleno medio día en medio del campo. Me acerqué a examinarlas y me tendí a la sombra de esa planta para observarla mejor. La visión del sol entre las hojas, los insectos que volaban como chispas, los árboles respirando inmensos y misteriosos y el silencio sin límites. Sentía la presencia de murmullos abandonados, juegos de niños y conversaciones, y ya no estaba bajo ese árbol. Me había transformado en árbol. Entré ciego de sol a la casa y, algo mareado, no pude hacer otra cosa que escribir mis primeros versos, y sin darme cuenta en ellos aparecía la música de Lorca. La naturaleza estuvo presente en el origen mismo de mi poesía como una emoción total, y el árbol pasó de inmediato a ser una figura central y viviente de mi poesía.

Nací en Valparaíso en 1942 en plena guerra, soy un hijo no sólo de la ciudad sino del puerto. Mis padres, un oficial de marina y una profesora de inglés, representaban bien una clase media chilena cultivada a la sombra de la guerra que llegaba por las noticias y las revistas. ¿Cuáles son los rasgos de la cultura chilena accesibles entonces en una biblioteca doméstica de clase media como esa que me sirvió de sustento? Una respuesta esquemática a esa cuestión nos dará el cuadro intelectual de mi generación. Este rodeo es indispensable para situar mi obra.

Había libros en mi casa y los libros de esa época de reciente postguerra formaban parte del universo mental de los traductores y exiliados españoles que desde 1936 trabajaban sin descanso en América Latina con el propósito de educar al pueblo, de poner a su disposición la mejor literatura posible. Los mismos ideales tenían ciertas formaciones políticas indigenistas en Perú o en México. Los exilios interiores de los latinoamericanos expulsados de un país a otro por golpes de Estado o dictaduras producían en los países de asilo nuevos traductores y editores locales y nuevas avalanchas de libros que convergían en una operación desmesurada de educación popular. Esa voluntad educadora y enciclopédica ya tenía antecedentes en el siglo XIX, cuando los primeros dictadores y caudillos provocaban el ir y venir de los intelectuales y de los escritores. Los latinoamericanos nacidos como yo en la guerra y formados en la postguerra asistían a una gran utopía pedagógica que se inscribe en el origen mismo del pensamiento y del ensayo histórico latinoamericano. Este tiene por objeto la historia y la geografía de América Latina interpretada por los mismos latinoamericanos. La sed de cultura es parte necesaria de la búsqueda de una identidad latinoamericana.

El período de eclosión del pensamiento latinoamericano puede situarse entre la publicación de los Siete ensayos de interpretación de la realidad peruana de Mariátegui, en 1927, y El laberinto de la soledad de Octavio Paz, en 1950. El Canto general de Neruda y las "Alturas de Macchu Picchu" son la evocación interpretada del mundo precolombino y de la historia latinoamericana desde el descubrimiento hasta 1950, y se inscriben también, según mi opinión, en ese mismo movimiento de toma de conciencia histórica. Los latinoamericanos se autointerrogan y analizan sus primeras utopías libertarias, su primer siglo de vida independiente y sus primeros fracasos. El problema que se les presenta ya no es España o Europa, sino la tierra y los hombres mismos de América Latina. No está de más recordar aquí que la publicación de la traducción de Caillois de las "Alturas de Macchu Picchu" es anterior a la edición de ese poema en español. Como en su tiempo ocurrió con la edición francesa del Cántico espiritual de San Juan de la Cruz. Esto lo digo para dejar planteada una cuestión lateral importante.

¿Qué lugar le corresponde a Francia en la búsqueda de una identidad latinoamericana y en la formación de sus escritores, intelectuales y poetas? Esa cuestión no vamos a responderla aquí, pero es indispensable formularla en el tema que estamos tratando. Porque la cantidad y la calidad de la producción literaria latinoamericana escrita en Francia y difundida en América Latina no puede ser considerada una simple coincidencia. En resumen, entre 1925 y 1950 los latinoamericanos manifiestan el deseo de reflexionar sobre su propia historia y de encontrar una identidad propia, correspondiente a la que cada país ha formado lentamente desde el siglo XVI. El representante chileno de ese movimiento, en el plano del ensayo, es Benjamín Subercaseaux y su libro Chile o una loca geografía que puede compararse con la Radiografía de 
la Pampa del argentino Ezequiel Martínez Estrada que completa el análisis visionario de Facundo de Sarmiento, obra que reflexiona sobre la identidad latinoamericana en contrapunto con la figura del caudillo Facundo Quiroga.

Gabriela Mistral, en el prólogo de Chile o una loca geografía, publicado en 1945, dice que Benjamín Subercaseaux es un formador de identidad. Ese juicio es válido y aplicable también a los poetas como Neruda y la misma Gabriela. Las bibliotecas latinoamericanas enriquecidas por los exiliados españoles de mediados del siglo XX, habían ya heredado la biblioteca francesa de los formadores de la república durante la primera mitad del siglo XIX y esas dos fuentes eran visibles en nuestras bibliotecas privadas de clase media, en la biblioteca del oficial de marina y de la profesora de inglés. Los notables de la independencia, entonces, tenían una necesidad imperiosa de saberlo todo, de irrigar el medio republicano con las ideas educadoras de la Ilustración tardía española, reformista y progresista. Buscaban recuperar el tiempo perdido en la colonia con el objeto no sólo de cultivar la literatura, sino también, y sobre todo, las ciencias necesarias a la administración del Estado y a la producción agrícola o industrial.

Nuestro siglo XIX todo lo copiaba de Europa, sobre todo de Francia y de Inglaterra. En Chile y Brasil los apóstoles de la humanidad predicaban entonces la buena nueva del positivismo francés y sus obras se difundían sobre la base necesaria del altruismo político. Lo que no impidió ninguna guerra. La exigencia de identidad que existía ya en el siglo XIX no era muy ajena a lo que se ha llamado "la invención de las nacionalidades" en el siglo XIX europeo; buscaba símbolos nacionales que sirvieran para cohesionar una historia llena de orgullo nacional $\mathrm{y}$, de hecho, idealizaba a los indios que en la práctica combatía. El pensamiento latinoamericano de la primera mitad del siglo XX hilaba mucho más fino, interrogaba mucho más hondo y llamaba en su auxilio a la poesía. Entre esos ríos de libros se formaron, por ejemplo, Jorge Luis Borges y Lezama Lima. Cada uno de ellos es un atajo a una inmensa biblioteca anárquica. Los exilados españoles completaban el conocimiento que nos daban los profesores de castellano publicando poetas menos conocidos que circulaban en las ediciones Cruz del Sur.

En 1960 yo conocía no solo a los surrealistas franceses que el surrealismo latinoamericano se había encargado de difundir, sino también, y aunque parezca increíble, a poetas alemanes contemporáneos como Ingemor Bachmann, Paul Celan o Yvan Goll traducidos por Vera Zeller en la revista Orfeo. La relación de Chile con Alemania y la cultura alemana es importante no sólo porque en Chile hubo una fuerte emigración alemana desde 1850, sino también porque los españoles exiliados desde 1936, sobre todo en México y Argentina, impregnados de historicismo traducían sin cesar filósofos, historiadores y literatos alemanes y no los identificaban en absoluto con el fascismo que los había expulsado de España. El catálogo de las ediciones del Fondo de Cultura Económica es la mejor demostración de lo que digo. Yo pienso sinceramente que una de las bibliotecas más completas del mundo es la biblioteca en lengua española.

Ya ven que este rodeo era indispensable para esbozar una base general de nuestra cultura literaria. Regresemos a la historia familiar.

Una hermana de mi padre se casó con un señor llamado Rafael de la Sotta Benavente de la más antigua aristocracia terrateniente chilena. Las haciendas familiares se extendían entre Concepción, Chillán y Cauquenes en toda la frontera con los indios araucanos. Yo pasaba mis veranos en casa de esa tía y allí vivía en el campo de acuerdo al rango de ser miembro lejano y pobre, pero miembro al fin, de esa familia. Durante el año iba al liceo que es la educación pública y gratuita chilena. Mi madre consideraba que esa educación era indispensable para todos los chilenos. En un país tan jerarquizado como Chile, el liceo es la escuela de los niños pobres y de la clase media baja. Mis compañeros de curso eran todos hijos de obreros. La madre de mi mejor amigo en toda esa época y hasta durante los años de universidad, era camarera de un hotel de Valparaíso. Todos los años yo recorría de alto a bajo la sociedad chilena y conocía desde adentro el comportamiento íntimo de sus miembros.

Mi madre no soportaba a los aristócratas y constantemente discutía con ellos de política y religión. A pesar de todo ellos la querían porque leía cuentos en voz alta, ponía inyecciones a los enfermos y enseñaba a leer a los numerosos niños de la familia. Pero mi madre es un caso particular de provocación y generosidad. Aceptaba difícilmente tener niñera y cuando la tuvo y supo que era analfabeta y tímida, ayudó a casarla con el asistente marino de mi padre, escribiéndole ella misma las cartas de amor que al parecer la niñera le dictaba, y después educó a sus hijos. Uno de sus hermanos fue un periodista bastante conocido en Chile y bastante provocador que escribía contra el general Ibáñez, el dictador de turno, y pasaba temporadas en prisión; otro hermano encontró que los ancestros de los Morales, que es el apellido de mi madre, eran judíos. Tuvo confirmación de sus investigaciones, escribió un largo texto hasta ahora inédito que llamó Los pinceles talmudistas, y se convirtió al judaísmo. Hoy está enterrado en el cementerio israelita de Santiago. Una hermana de mi madre era casi una monja católica, lo que contrapesaba las fuerzas religiosas de esa familia. Mi madre tenía lo que ella llamaba "una religión propia" que era más moral que religiosa en realidad. A pesar de ello, tenía muchos amigos curas que la apreciaban porque podían contar con ella para sus obras 
sociales y porque tenía un gran coraje. La menor era abogado y, según mi madre, la encarnación del desorden. Yo amenazaba a veces a mi madre con escribir un libro que llamaría La locura de los Morales.

Lo curioso es que esa familia bastante laica y libertaria tenía una buena cantidad de miembros militares. Mi abuelo paterno había sido un oficial importante, con estudios en Francia, y mi abuelo materno había sido director de la Escuela Naval de Valparaíso.

Los indios, por supuesto, forman parte del mestizaje chileno y del mío, pero a los indios nunca se les nombra en Chile. Son la raíz desconocida. Ya volveremos a esta invisibilidad característica del ancestro principal.

Al lado de la cultura de los libros estaba la naturaleza. La naturaleza chilena es a la vez formadora de identidad y fuente de poesía. Hay en ella una energía que puede ser devastadora. Las ciudades chilenas son, en general, bastante feas. Mi amigo Armando Uribe afirmaba que existe en Chile el culto de lo feo. Como si los habitantes se hubieran preguntado: ¿Para qué hacer algo hermoso cuando es posible hacerlo feo? Sin embargo, esas ciudades se transforman para el que las habita en lugares bellísimos o, mejor aún, en lugares de los que los hombres se enamoran, como el puerto de Valparaíso.

Hay grandes zonas de silencio en Chile. Estoy convencido de que el silencio es una forma de expresión de la naturaleza y lo que escuchamos, adivinamos o interpretamos en ese silencio, es indecible y puede ser violento hasta casi rompernos los oídos. En ese silencio se escuchan vibraciones, ultrasonidos que las cosas no parecen producir en la realidad audible. Los cielos estrellados del Norte de Chile, por ejemplo, producen un sonido de colmenas o burbujas; otras veces hay lamentos y cantos de ballenas que nadan en el cielo del Sur y del extremo Sur. Son una parte de la naturaleza las sensaciones y los sentimientos que ella nos provoca. El sentimiento de la soledad, por ejemplo, o el de abandono y su contrapartida; la intuición de presencias invisibles de seres que pueblan la noche campesina. Esa inmensa noche sin electricidad, con lámparas a parafina rodeadas de polillas y de estrellas.

Los animales y los árboles son seres unidos al enigma de la vida, densos de conocimientos, que sólo se trasmiten como los de los enamorados, por telepatía. La naturaleza enseña rápidamente el aspecto doble de la vida, la belleza tiene su contrapartida en la crueldad; la vida, en la muerte; la fuerza y la salud, en las enfermedades que parecen pesadillas como el carbunclo que, según la costumbre, se combate quemando los animales muertos. Los terremotos han traumatizado para siempre a todos los chilenos. Los dioses aztecas son siempre buenos y malos a la vez.

Yo creía que esa naturaleza vivía. La demostración me la dio mi padre. Un día puso su disco en el fonógrafo, era la sonata "Appassionata" de Beethoven. Me llevó a la ventana y me mostró los árboles: Mira -me dijo-, los árboles se mueven con la música. Yo pasé horas mirando hasta estar completamente convencido de esa verdad.

Mi madre tocaba el piano, yo escuchaba embelesado los nocturnos de Chopin y muchas veces me acerqué a ese instrumento que guardaba la resonancia de un teatro oscuro y abandonado. Donde el gesto mínimo hace aparecer la vibración, y el eco levanta hollín y polvo. Yo me sentaba y buscaba durante horas esas vibraciones.

A mi descripción de la naturaleza le falta algo muy importante, el mar. Nací y crecí al lado del mar siguiendo sus aventuras, escuchándolo y sintiéndolo. A veces esas revelaciones eran cuerpos flotando a la deriva, cosas que brillaban en la marejada, pedazos de medusas o calamares. La escuela de mis primeras letras colindaba con el mar y en ese mar flotaba muy cerca un acorazado peruano capturado en 1879: El Huáscar.

Desde niño ya estaba decidido a ser poeta y así se lo escribí en una copia a una profesora que nos pidió decir qué deseábamos ser cuando grandes y cómo creíamos que la escuela nos ayudaría a cumplir nuestras ambiciones. Había que señalar tres opciones. Las mías fueron: poeta, violinista y faquir. Una cosa curiosa, a pesar de mi gran atracción por la música, nunca pude cantar una sola nota.

Ya están los elementos importantes de mi formación de poeta más o menos presentados.

Chile no sólo se divide entre ricos y pobres, sino, sobre todo, entre indios y mestizos que se sienten blancos. El conocimiento que tuve en mi infancia con los inquilinos de origen mapuche fue parte de mi aprendizaje de la sociedad y de la naturaleza, porque los indios formaban parte de ese gran silencio y de esa naturaleza misteriosa y siempre presente. Mis lecturas se ahondaban y desarrollaban según el mismo sentido arborescente y laberíntico que había empujado a los editores a publicar y a los escritores a escribir y traducir, guiados todos por la curiosidad, la intuición y la utopía de una paideia latinoamericana.

El último año de liceo hubo un vuelco en mi aprendizaje. Mi madre nos puso a mi hermana y a mí en una escuela religiosa francesa; estaba aburrida por las huelgas. Ella pretendía que sus alumnas de humilde origen 
dejaran el liceo hablando inglés. Quizás ponernos en los Sagrados Corazones fue parte de su espíritu de contradicción y de provocación. Allí aparece otro elemento de esta formación intelectual y poética que estoy esbozando someramente. La religión católica. Yo había sido el único alumno del liceo que se negó a tener cursos de educación religiosa, cursos que eran optativos y no obligatorios gracias a los avances de los radicales y masones en el Ministerio de Educación. El conocimiento de La Biblia no era nuevo para mí y me apasionó como podría haber apasionado a un converso. Los conventos campesinos y los retiros espirituales de los padres franceses me encantaron. Me sentí religioso y católico, y antes de entrar a la universidad fui cooptado de inmediato por uno de los tantos movimientos católicos de la juventud.

Sin embargo, no había abandonado un cierto espíritu independiente. En la clase de dibujo hacía mis propios dibujos. Trabajaba mucho más que los otros alumnos, pero los dibujos que yo hacía no eran los que el profesor pedía, que me parecían terriblemente banales. Lo peor era que el profesor y yo nos teníamos una gran simpatía y yo era exactamente lo contrario de un alumno exaltado, conversador, distraído y poco interesado en su curso. Yo trabajaba en silencio y concentrado. Después de varias expulsiones admitió que presentara mis dibujos a examen y desde entonces dibujo y pinto cuando no escribo.

En la Universidad Católica que dirigían los jesuitas estudié Historia y Derecho. Había abandonado, después de un año, el movimiento católico que se interesaba bastante poco en mis estudios bíblicos. A causa de las cuestiones bíblicas fui considerado culpable de que mi grupo no hiciera ningún progreso espiritual durante un año.

Mi compañero de banco en el Liceo, el hijo de la camarera, me había sugerido muchas veces la necesidad imperiosa de un compromiso político. En las elecciones de 1973 voté por Allende. Algunos de mis alumnos en la Universidad Católica eran miembros de las Juventudes Comunistas. Sabían que yo me había inscrito para hacer cursos gratuitos durante las vacaciones en la escuela popular de verano. Se me acercaron y me enviaron un auténtico obrero para dialogar. Había en la universidad ya un profesor comunista de ingeniería. Yo fui el segundo. El tercero fue el director del Instituto de matemáticas. Como comunista yo hacía emisiones en la radio "Caupolicán", dirigía la revista de las escuelas de derecho, era vicepresidente de la organización de mi barrio para el aprovisionamiento de comestibles y, con los demás profesores de mi grupo, participaba en los trabajos voluntarios que consistían en limpiar las bodegas portuarias de Valparaíso.

A mis alumnos de la Escuela de Derecho yo les decía que el odio y el racismo envejecen prematuramente a las personas y, sobre todo, arrugan la piel de las muchachas jóvenes; las muecas de desprecio no se borran nunca. Cuando el golpe vino yo ya había hecho méritos suficientes para ganarme la "beca Pinochet" y además para pasar a los interrogatorios de la Academia de Guerra. Los profesores me denunciaron, pero los alumnos me defendieron diciendo que yo nunca les había hablado de política en mis cursos.

En los años setenta Heidegger y el marxismo se habían agregado a mis conocimientos. Pero afortunadamente en el choque que provocaron esas dos galaxias se anularon recíprocamente y desaparecieron. Examinando ahora las ruinas invadidas por las malezas que dejaron en mí esas influencias reconozco el valor estético de la reflexión. Heidegger nos iluminaba con su lenguaje de escultor a la búsqueda de la experiencia originaria del pensar, la angustia, la nada, el aburrimiento, eran experiencias metafísicas importantes que se ganaron un lugar en la formación del poeta y del filósofo contemporáneo. En cambio, el marxismo somero de los manuales soviéticos o las abstracciones de Althusser, Balibar, Nicos Poulantzas o, peor aún, de sus alumnos y de los alumnos de los alumnos, terminaban cansándonos con sus catecismos. Lo peor es que según ese marxismo, la cultura y sobre todo la literatura y la poesía eran siempre sospechosas del delito o del pecado, no sólo de pertenecer a la clase dominante, sino de jugar un papel en la represión. Por suerte, la existencia de poetas italianos muy "comprometidos" como Pavese, Pratolini, Pasolini y sobre todo Ítalo Calvino, contradecían ese monumento de falsedades que circulaba entre nosotros produciendo estragos. Parte de la crisis vivida en ese momento era consecuencia del increíble desdén por la literatura y por la cultura, que se pretendía desenmascarar para evitar sus efectos nocivos de instrumentos de las clases opresoras. Fuera del marxismo, la epidemia sociológica norteamericana tenía los mismos objetivos y la misma convergencia que el marxismo que combatía: desacreditar el pensamiento latinoamericano ligado a la historia y a la literatura, dar un rol muy secundario a la historia y a la cultura de origen latino.

El pensamiento "científico" tiene una larga tradición en América Latina, ya en el siglo XIX el lema "orden y progreso" de Augusto Comte pasó a ser bandera de la modernidad de los militares brasileros. La sociología no vaciló nunca en unirse a las dictaduras que se decían progresistas como la de Porfirio Díaz en México. En los años sesenta, según una versión de esa misma mentalidad, "el desarrollo" exigía prioridades y opciones, lo que significa en claro ideas y personas que había que excluir. En las prioridades culturales destinadas al desarrollo, la literatura era la última y la menos importante. Un verdadero combate se produjo en esos años entre sociología e historia para disputarse el pensamiento latinoamericano. Sólo un sociólogo logró escapar a ese maniqueísmo: el brasilero Gilberto Freire. Ni siquiera mis amigos jesuitas escaparon a una manera de pensar que nos hundía a ojos vista en el subdesarrollo cultural sin sacarnos del subdesarrollo 
económico. Afortunadamente bastaba acercarse a una librería de libros viejos de Valparaíso para encontrar intacto el laberinto de los libros antiguos con sus minotauros poetas.

¿Cómo la poesía encontraba en esos años tan poco favorables los medios de subsistir y de trasmitirse? Si la poesía fuera una planta no sería ni rosa, ni lirio de jardín, sería maleza; si fuera perro no sería faldero, sino el perro vagabundo de Cervantes que busca compañeros para contar su vida. La manera cómo conocí la obra de Constantino Kavafis les dará una idea de lo que afirmo. Siendo estudiante de liceo entré en una peluquería de Valparaíso. Esos lugares tienen un mobiliario y, sobre todo, olores que se reconocen y persisten y son más o menos semejantes en todo el mundo. Esa misma peluquería podía existir en Alejandría de Egipto. El mismo olor de agua de colonia, talco, metales asoleados, cuero. Los mismos reflejos azules en el espejo. El peluquero con el bigotito recortado y la peineta estrecha y terminada en punta en el bolsillo superior de su chaqueta blanca, era también un personaje universal de la mitología cotidiana.

Mientras esperaba mi turno escuchando el desagradable ruido de la máquina, tomé una revista del montón destinada a los clientes. Era una revista verde oscura, no por razones estéticas, sino porque era una publicación de los carabineros y ellos usan un uniforme verde. En Chile casi todo lo que se pinta de color verde tiene alguna relación con la policía y no con la primavera o con la esperanza. La revista se llamaba Revista del tránsito. No había nada que leer en ella. Unas cuantas fotografías mostraban Valparaíso inundado como todos los inviernos y los porteños transformados en pálidos fantasmas. La fotografía y el papel eran pésimos. De pronto descubrí un poema que ocupaba toda una página. Lo leí. El poema se llamaba "Ítaca"; el autor, Kavafis; el traductor del poema, Jorge Razis, cónsul de Grecia en Valparaíso. El peluquero, impresionado, me regaló la revista. Días más tarde fui a ver a Razis después de mis cursos en la tarde. El consulado quedaba frente a la plaza Victoria en un segundo piso de uno de esos palacios victorianos a mal traer que abundan en Valparaíso. Me acerqué al mesón y un funcionario me preguntó qué deseaba, le dije que deseaba ver al señor Razis ¿Con qué objeto?, me preguntó. Kavafis, le dije. El hombre entró en una oficina y me invitó a pasar. Detrás de la mesa se levantó un hombre bajo vestido de negro que no sonreía y que, sin embargo, me esperaba. Encontré su poema en la revista de los carabineros, le dije, como explicación de mi presencia. Me hizo sentar mostrándome el sillón delante de su mesa y sacó del bolsillo interior de su chaqueta una inmensa billetera usada. En ella no tenía dinero, sino papeles recortados: eran poemas de Kavafis. Yo los leía y él esperaba que yo depositara la hoja en la mesa y me pasaba otro. Casi no hablamos. Pienso que el señor Razis esperaba, y con razón, que eso ocurriera. Era inevitable que un poeta de Valparaíso leyera algún día la traducción publicada en la revista de los carabineros encontrada en un mercado o en la sala de espera de un dentista y que después viniera a pedirle el resto de los poemas que él había traducido. Por eso yo tenía la extraña sensación de ser esperado. El puerto de Valparaíso ya no era el mismo al salir del consulado y atravesar la plaza Victoria. Kavafis lo había llenado con recuerdos de un lugar donde nunca estuve.

De esa misma educación clandestina y autodidacta formaban parte los amigos. Uno de ellos en particular sufría o, mejor dicho, gozaba del insomnio. Cuando todos los cafés estaban cerrados, alguien proponía, vamos a ver a Alfonso, y Alfonso nos abría la puerta a cualquier hora de la noche, completamente vestido y sin una gota de sueño, con un libro en la mano. Alfonso nos leía traduciendo algún autor o poeta inglés o francés, o entrábamos en discusiones filosóficas escuchando Brassens, Hindemith, Honneger, Prokófiev, Stravinski y Ravel. En esa época todavía se aceptaba poco Chopin, apenas Khachaturian y menos todavía Rachmaninoff o Tchaikovsky. Esas reuniones podían terminar al alba.

En forma casi clandestina me había ligado a algunos poetas de Valparaíso que se reunían en la trastienda de un librero. Había publicado algunos poemas en una imprenta y escrito algunas cortas memorias de grado. Una sobre la relación entre historia y poesía en Saint John-Perse en la Facultad de Historia y otra sobre la interpretación histórica de la ley en la Facultad de Derecho. En el momento del golpe yo era un joven asistente de Historia del Derecho, de Historia Moderna y de Teoría de la Historia, me había casado con una compañera de curso asistente de Derecho civil, teníamos dos hijos y era el único profesor comunista de la Facultad de Derecho de la Universidad Católica de Valparaíso. Al día siguiente del golpe militar perdí todos mis trabajos en las dos universidades. Los militares iniciaron, además, un proceso contra mí. No quise o no pude partir en ese momento y pasamos el año vendiendo los libros, los muebles y los discos a los colegas universitarios. No les guardo rencor, lo peor hubiera sido que no me compraran nada. El señor Bihoreau de la embajada de Francia y el profesor Ruggiero Romano de la Escuela de Altos Estudios en Ciencias Sociales de Paris, me ayudaron a salir de Chile. Les agradeceré toda mi vida. Tenía además una ayuda de la fundación Ford que me permitiría partir con mi familia. 
Algunos profesores, miembros de una organización de profesores de derecho llamada Internacional Legal Center financiada por la fundación Ford, trabajaban en Chile para cambiar las normas de la enseñanza del derecho en las universidades. Se trataba de una vasta operación destinada a americanizar el derecho latinoamericano en general. La reforma consistía en pasar de la norma y del sistema al caso, y abandonar el derecho codificado, que es en gran parte de origen francés. Les agradezco a ellos no sólo la ayuda que me permitió partir de Chile, sino también haber podido conocer y visitar la bellísima casa de Neruda que los profesores del Internacional Legal Center arrendaban al lado del cerro San Cristóbal. Confieso que como comunista militante esa flexibilidad del pensamiento marxista no dejó de impresionarme.

En el fondo de los dos grandes baúles llenos de libros que me llevaba a Francia dormían tres libros: una antología de poetas de Valparaíso, Alianza, en que yo había publicado una serie de poemas a los 18 años, en 1960, y dos plaquetas publicadas por mí en una imprenta: La pieza con luz, en 1961, y Las palabras encima de la mesa, en 1972. El primer poema de este último librito se llamaba "Tierra próxima" y el último "Territorio de asombro". Los dos habían ganado concursos poéticos de Valparaíso. Ese cuadernito muy feo sería decisivo en mi vida. En el momento de cruzar la pasarela del Donizetti tenemos Valeria y yo 32 años, es el 4 de septiembre de 1974.

Al publicar Las palabras encima de la mesa en 1972 mi poesía está ya definida en lo esencial. El primer poema de esa colección es "Tierra próxima". Roger Caillois va a traducir este poema y va a hacerlo publicar en La Nouvelle Revue Française, en 1977. El último poema de esa misma colección, "Territorio de asombro", había ganado el primer premio del concurso de poesía de la Sociedad de Escritores de Valparaíso, en 1965. Benito Pelegrín va a traducir esta serie de poemas y va a hacerlos publicar en la revista Solaire, también en 1977.

El puente del Donizetti se retira lentamente y el espacio entre el barco y el muelle se dilata y se transforma en infranqueable. A partir de ese momento el exiliado iniciará el largo meditar sobre el país perdido. Es una meditación llena de riesgos. El viaje, sin embargo, era ya una manera nueva de ver el mundo y América. Hasta entonces mi único viaje había sido a la Isla de Pascua y yo afirmaba que no había ninguna necesidad de viajar lejos para vivir plenamente una cultura, lo que es una aberración. Después del golpe había pedido sin éxito a mis ex colegas de la Escuela de Derecho transformados en jueces que me exiliaran en la Isla de Pascua, pero no quisieron. Pronto nos dimos a conocer en el barco el grupo que partía por fuerza y por razones políticas a destinos desconocidos. Muchos tenían malos recuerdos, pero el Donizetti nos ofrecía una verdadera vida de trasatlántico de lujo. Durante un mes vivimos todos como falsos millonarios. Yo pasaba el tiempo leyendo en ediciones bilingües a Saint-John Perse y Salvatore Quasimodo, con la vaga intención de aprender francés o italiano. Remontar la costa de América del Sur hasta el canal de Panamá y atravesar el Atlántico me permitió reconstruir mi mundo isleño, agrandarlo, y tomar conciencia de él y de la extraña geografía chilena que es también una isla. Se hablaba ya de "los de adentro" y "los de afuera". El Donizetti atravesaba la línea del Ecuador y, con el bautismo tradicional, el grupo de los exilados pasaba a ser parte de "los de afuera".

Los indios araucanos con su religión chamánica, su origen amazónico y sus costumbres culinarias polinésicas son una convergencia cultural dentro de la isla geográfica que es Chile. No es de extrañar que en una isla la espiritualidad esté ligada al trance, al viaje y al regreso. Todas las islas miran al cielo y dan ganas de volar, y cuando se dejan, ganas de regresar.

El Donizetti llegó a Niza el 4 de octubre de 1974, después de un mes de navegación. El verdadero exilio iba a empezar entonces y en primer lugar el exilio de la lengua. El momento de mayor necesidad de comunicación para el exiliado es el de mayor debilidad y el que exige el mayor esfuerzo. En Paris fui recibido por un ex rector de la Universidad de Chile de Valparaíso, el señor Martínez, comunista y arquitecto. Me explicó el funcionamiento del Metro. Yo había sido uno de sus colaboradores cercanos. Mis compañeros comunistas de la Universidad de Chile, con el mismo rango universitario y sin haber obtenido un doctorado, habían sido acogidos y distribuidos en las universidades francesas y habían obtenido la posibilidad de continuar sus carreras universitarias. Era lo que yo esperaba. Martínez me anunció directamente que para mí no habría posibilidad de un cargo de profesor asistente en las universidades francesas y que tendría que buscar trabajo por mis propios medios. Nunca entendí por qué fui descartado de esa forma por los dirigentes políticos del exilio. Había dejado Chile con una gran confianza en los dirigentes de mi partido y en mis profesores, el profesor comunista Andrés Orrego Matte del que era asistente en la cátedra de Historia Moderna y de Teoría de la Historia. Sin el apoyo político era inútil intentar entrar a la universidad. Espero que algún día sepa la razón de esa actitud que tendrá consecuencias directas en mi 
propia identidad de poeta. El boleto de metro del señor Martínez fue la única ayuda que me dio el Partido Comunista, al que pertenecía, para instalarme en Francia.

Yo había renunciado a un cargo de asistente de Derecho Romano e Historia del Derecho en la Universidad de Sassari y había preferido exiliarme en Francia. Era seguramente lo que debí haber hecho. Ahora estaba confrontado a una situación gravísima que se agudizaría cada día más y que comprometía a mi familia. ¿Qué podía hacer? Nos instalaron provisoriamente en un foyer obrero de Villejuif y me anunciaron que tendría que pagar esa residencia con la ayuda que me daría el gobierno francés de Giscard d'Estaing una vez que me asilara. Envié una carta de ruptura al ex rector y al partido que me trataba como un desconocido y pensé en lo que se imponía con urgencia. Tenía que irme, por no decir, escapar, lo más pronto posible del foyer de la Villejuif. Mi llegada a Paris había sido violenta. Debía actuar ahora contando sólo con mi mismo y con mis relaciones. Por el momento era todavía un becado del gobierno francés. Escuché por casualidad en un restaurant una conversación, alguien iba a dejar un departamento en Paris. Era una pareja de bailarines de la ópera. Les dije, prácticamente en el lenguaje de los sordomudos, que yo buscaba un alojamiento y que les arrendaba esas dos piezas. Me dieron un teléfono y una dirección: Diane Costa de Beauregard, rue de la Tremoille. Era la propietaria. Llamé por teléfono. Una mujer joven no entendió una sola palabra de lo que yo decía y me preguntó si yo era de origen vietnamita. Le dije que pasaría a verla a su casa. Era un inmenso departamento. Una joven señora muy cortés me recibió, conversamos algo y llegamos a un acuerdo. Ella me arrendaba el departamento del 22 de la rue Rousselet. Le di un mes por anticipado y otro de garantía. Regresé feliz a la Villejuif. Valeria, le dije a mi mujer, hemos arrendado un departamento en el centro de Paris, ahora podemos irnos. Estupendo. Hasta he pagado dos meses. ¿Tienes un comprobante? Se me había olvidado pedir un recibo a Diane Costa de Beauregard, pero ella también se había "olvidado" de pedirme una justificación de mis recursos.

Tenía que encontrar pronto un modo de dejar el foyer. Conocí a dos franceses que ayudaban a los chilenos; con ellos asistí a mi primera fiesta francesa. Los dos habían participado en el movimiento estudiantil de mayo del 68 y escuchaban religiosamente discos de canciones de esa época. Ellos me sacaron de la Villejuif y me vi instalado en el 22 de la rue Rousselet en el centro de Paris. Al frente de nuestro departamento había vivido Barbey d'Aurevilly. Mis niños se inscribieron en la escuelita primaria de la rue Vaneau, donde había vivido Gide. Los bailarines me dejaron algunos muebles y me explicaron el funcionamiento de la calefacción. Esta era una espesa cortina de minúsculas perlitas blancas atravesada por una fina resistencia eléctrica y cubría completamente las ventanas. La cortina se enchufaba y calentaba perfectamente el departamento. Un día que hubo que repararla y el electricista me dijo asombradísimo ¿Eso lo trajo usted de su país? Íbamos a vivir dos años y medio en dos piezas, una rosada y una gris. Las paredes estaban cubiertas de seda de esos mismos colores. Una cortina separaba los dos ambientes, naturalmente la cortina era por un lado gris y por el otro rosada. Como un teatro de marionetas. Los niños estaban felices.

Rápidamente llegamos al meollo de esta charla autobiográfica que, como todo lo autobiográfico y vivo, tiende a un modelo arborescente. ¿Cómo me hice poeta?

El partido no me había escogido entre los intelectuales que valía preservar para que produjeran sus obras, como se estipulaba en esos casos. Había perdido los lazos políticos con los comunistas y con los mecanismos de ayuda para los exilados. La beca solo duraría dos años y era apenas suficiente para vivir, no teníamos tiempo, ni siquiera para angustiarnos. Por otra parte, el regreso a Chile no parecía posible en un tiempo corto. China había sido uno de los primeros países en reconocer a Pinochet y le había hecho además un gran préstamo para ayudar a su gobierno. Eso era políticamente incorrecto saberlo, y quizás lo sea decirlo incluso ahora mismo a pesar de los años, pero si una ventaja yo había obtenido era el derecho de ser políticamente incorrecto. Es necesario aclarar este punto. El pensamiento políticamente correcto es el que sirve ese poder, esto es, no sólo sigue las consignas del partido, sino también los intereses de los dirigentes, evitando la crítica que pudiera afectarlos. El poder es, además, personal y administrativo. Es necesario estar cerca de él y saber usar los mecanismos. Hay un modo de empleo de la condición de exiliado. Los dirigentes políticos del exilio habían decidido no ayudarme quizás porque yo desconocía la forma de ser un buen exiliado.

Miles de preguntas políticamente incorrectas me asaltaban: por qué Allende no se había limitado a lo fundamental, a la nacionalización del cobre chileno que las cámaras habían votado por unanimidad a pesar de que la izquierda era minoritaria. Por qué Pinochet no había devuelto las minas a los americanos si estos lo habían puesto en el poder con ese objeto. Por qué Allende no había nombrado en su gobierno a ni un solo embajador o alto funcionario de origen mapuche si quería cambiar la sociedad chilena dividida secularmente. Por qué invitaba a Fidel Castro a Chile y se fotografiaba levantando una ametralladora en la mano si era 
demócrata y pacífico como todos sabíamos. Por qué no se formó de inmediato un gobierno chileno del exilio como había hecho España, etc. Ese tipo de elucubraciones interminables son típicas de la experiencia del exiliado y de ese choque de poderes reales y fantasmagóricos que forman parte de su vida.

Pero, a pesar de nuestros problemas y de ser o no políticamente correcto, qué revelación fue Paris para nosotros y para el joven lector y escritor que yo era entonces. Me inscribí no sólo en los cursos de Romano, sino también en los de Laplanche, Picon, Pomien y Villey. De todos ellos, fue el curso de Gaëtan Picon el que cambió mi vida y mis proyectos. En su seminario sobre el surrealismo presenté el tema que me interesaba desde Chile. La coherencia de la obra de Roger Caillois. El tema gustó mucho a Gaëtan Picon y me dijo que le escribiría a Roger Caillois para que me recibiera. Yo conocía y admiraba la obra de Caillois traducida al español, sobre todo sus trabajos sobre la imaginación en la naturaleza, la imaginación justa, las ciencias diagonales. Mi baúl con libros había llegado a la rue Rousselet; el día de nuestra entrevista escogí llevarle de regalo un libro de un misionero franciscano. El padre Sebastián Englert a quién yo había conocido en la Isla de Pascua. El libro se llamaba La tierra de Hotu Matu'a, era una gramática de la lengua de la Isla de Pascua editada por la imprenta de los padres Salesianos de Valparaíso. Esa gramática daba ejemplos de formas de clasificar los objetos de la naturaleza, eficaces pero no científicas. Ese tema estaba en el centro de las reflexiones de Roger Caillois. Los pascuenses clasificaban las nubes según el objeto al que se parecían. Había una categoría de nubes que parecían estatuas que se desploman cuando el sol se pone.

Caillois me recibió en su departamento de la avenida Bosquet, me hizo pasar con un gesto cortés y algo aburrido, pero cuando le mostré el libro del padre Sebastián Englert cambió completamente de actitud. Conversamos de sus piedras, de sus viajes, de los objetos que le servían para soñar. Hablamos de todo salvo de la memoria que yo tenía que hacer. Continuamos viéndonos con un resultado parecido. Un día me decidí a mostrarle Las palabras encima de la mesa, el feo librito que dormía en el fondo del baúl. Una semana más tarde me dijo que el primer poema, "Tierra próxima", le interesaba mucho y que pensaba traducirlo para publicarlo en La Nouvelle Revue Française. Estábamos en 1976 y la traducción apareció en 1977.

Caillois se convirtió en la gran puerta de entrada de mi reconocimiento como poeta en Francia. Era, además, un maestro original, un pensador vivo. Un día había comprado un diente de Narval, es decir un cuerno de la Licorne. Durante varios días quería saber todo lo que se había escrito sobre la Licorne, pero días más tarde lo había devuelto. ¿La razón? No me hacía soñar, me dijo. La traducción de Caillois era también una exigencia poética. Comentando uno de mis poemas, me dijo: Esta estrofa es muy buena, pero no tiene nada que ver con el poema. Me costó dos días admitir que tenía razón. Supe que Octavio Paz había hecho lo mismo que yo. Caillois me ofreció transcribir la correspondencia entre él y Gabriela Mistral, que estaba escrita a lápiz y se estaba borrando. Cosa que pensamos hacer más tarde. Era un filósofo de un tipo especial, algo arcaico, cercano a los espíritus del siglo XVIII. Hablando una vez de la fascinación de las imágenes vistas por un telescopio o por un microscopio, me dijo: En realidad descubrí que las cosas me son agradables en la proporción natural, vistas como son al ojo desnudo.

Los Costa de Beauregard nos invitaron a una fiesta en su casa. Allí conocí a otra serie de personas, entre ellas a un admirador de Borges y de Caillois. Thierry Gaudin, Ingeniero jefe de la Escuela de Minas. Le dije que yo conocía personalmente a Caillois. Si quería conocerlo yo le diría y pudríamos almorzar juntos. Fijamos una fecha y un restaurante. Caillois estaba feliz con la idea, fuimos a almorzar juntos y después me agradeció por haberlo hecho conocer a esa persona tan interesante. Allí me aconsejó que ya no dijera más que era profesor de historia, sino simplemente poeta y escritor. Uno de los primeros consejos de Caillois fue el de publicar en revistas literarias; es allí donde se mantiene viva la poesía antes de publicar en libros. Ese consejo lo he seguido hasta ahora. Después de publicar Poema del Sur, en 1982, entré en contacto con la revista Poliphonia que me pidió mi colaboración varias veces, pero también Creación, Entailles, Arpa y otras. Está bien claro que son esas revistas, y los pequeños editores, quienes hacen la verdadera vida de la poesía en Francia. Es raro que las grandes editoriales publiquen poesía. En el mejor de los casos viven sobre el fondo del pasado.

Mi trabajo, aunque limitado y siempre incierto, en la radio francesa, me permitía tener seguridad y derechos sociales como escritor. Una amiga periodista, me dijo que mi actitud de entusiasmarte por todo, de no amargarme y de no quejarme, no me iba a servir mucho para obtener alguna clase de ayuda. Mi consejo es que te compres un bastón y que aprendas a caminar arrastrando una pierna, me dijo.

El primer escritor francés que conocí fue Jacques Borel, su hija Ana cuidaba a nuestros hijos en la escuelita de la calle Vaneau. Tenía una casa fabulosa donde había un auto enterrado en el jardín y un caballo que se paseaba entre las flores. Los abuelos lo alimentaban con baguettes. ¿La única función del caballo es ser acariciado? le pregunté. Exactamente, me dijo Jacques. Caillois me preguntó, por entonces: Qué piensa usted de los franceses. Son algo locos, le dije. Es extraño que en tan poco tiempo haya calado tan hondo, me respondió muy serio. El término locura equivale a lo no racional y a lo imaginario. Si hay una locura de ese tipo en América Latina, también la hay en Francia y, sobre todo, en la Francia profunda. Y si había una 
identidad común a pesar de las variedades de América Latina, también había una variedad de francias en Francia y hasta de parises en Paris, cosa que continúo explorando hasta hoy día.

Una amiga chilena de Valeria estaba casada con un hijo de Jean Supervielle, hijo del poeta Jules. Él dirigía las emisiones de lengua española. Gracias a él entré a la radio a trabajar con Severo Sarduy y Emilio Sánchez Ortiz en un programa semanal de crítica literaria. Severo me dio sus consejos para vivir en el mundo literario de Paris. Nunca compres un libro. Los libros te los darán siempre. Desconfía del hombre que te dice "Je suis débordé". Las personas que cuentan siempre tendrán algo de tiempo disponible para verte a ti. No te preocupes de las faltas de ortografía, eres tú el que escribe y eso es lo que cuenta. Emilio y yo escuchábamos sus anécdotas después de cada emisión. Yo lo admiraba, sobre todo, por su sentido del humor y porque no tenía miedo a atribuirse el rol del ridículo o del ingenuo en los cuentos divertidos que contaba. Severo nos hablaba del gran mundo literario de Paris que él conocía al revés y al derecho. Su memoria era fabulosa; era capaz de completar un discurso ya grabado agregando exactamente las frases necesarias.

Mi poema fue publicado en La Nouvelle Revue Française en 1977 y me ayudó bastante a darme a conocer en el medio francés. Pero habían pasado ya dos años y la beca se terminaba. Un doctorado comenzado con Ruggiero Romano sobre la educación en Chile, estaba lejos de terminar. Había publicado en la revista Creación un segundo largo poema traducido por Caillois. Uno a uno, mis libros aparecían y, de vez en cuando, mis emisiones de radio, pero no tenía trabajo estable, en el fondo vivía de mi imaginación. Valeria no podía trabajar en Francia. Yo no podía trabajar en Chile. No podíamos poner en peligro los niños. Decidimos separarnos. Valeria podría vivir en Chile con su familia mientras yo me acomodaba en Francia por mis propios medios. Pero en Chile las cosas no eran en absoluto fáciles. El hecho de estar casada conmigo le quitaba la posibilidad de obtener cargos y ayuda. Valeria se asoció con un abogado que trabajaba en la protección de personas perseguidas y obtuvo un cargo de defensa judicial de personas sin recursos, en un pueblito lejos de Valparaíso.

Todos los años yo regresaba a Chile tratando de repetir siempre el mismo itinerario. Buscando el viaje más barato que el mercado de los charters podía ofrecer. Charters que atravesaban tempestades increíbles en las Antillas al final desembarcaban en Chile. Todos los años, más o menos a la misma fecha sin cambiar de itinerario. Ese viaje me mantenía ligado a la evolución política de Chile.

Me había ya dado a conocer en Francia en revistas de prestigio y estaba traducido por un escritor al que admiraba y que había traducido pocos poetas. Mis libros habían tenido muy buena acogida por la prensa y eso me abría las puertas de otras publicaciones. Los partidos políticos en el exilio me habían negado toda asistencia, pero tuve y tengo otros aliados que me ayudaron a hacer mi obra. Mi obra existe gracias a las mujeres que vivieron conmigo y que me permitieron hacerla. Ellas reemplazaron el apoyo político que no tuve. Empezando por Valeria, que me recibía y que conservaba la relación con Chile y con mis hijos. Yo quisiera nombrarlas a todas y decirles lo que mis libros les deben, pero ellas desean por el momento conservar el anonimato.

Como en Chile mis amigos pertenecían a todas las clases sociales, de alguna manera empezaba a comprender o, por lo menos, a distinguir los aspectos de por qué en Paris los escritores latinoamericanos se instalaban para escribir y lo lograban. Desde el siglo XIX, desde Heredia y Darío hasta Fuentes y Vargas Llosa. Claude Couffon había conocido y traducido algunos. No siempre se trata de un nombramiento diplomático. En Francia y Paris había un respeto por el escritor y una posibilidad de realizar el imaginario. No era el caso de Chile que, sin embargo, tiene dos premios Nobel.

En France Culture he podido hacer algunas emisiones sobre mis obras. La falta de reconocimiento chileno ha estado bien compensada por el reconocimiento francés. En Francia obtuve varias veces las ayudas del Centro Nacional del Libro y gracias a eso pude escribir y publicar. Y hasta viajar. Gané la primera beca dada por un instituto cultural franco español. Escribí un libro, El paso de las nubes, que ganó el premio Jean Malrieu al mejor libro de poesía traducido en Francia. La comisión eran los amigos del sur, agrupados hoy en la revista Autre Sud. Entre esas becas ha estado la ayuda considerable de Henriette Zoughebi. El año 1992 publiqué gracias a una beca una serie de libros. Mi novela traducida en otros países, mi ensayo sobre la indignidad, la antología de la poesía precolombina con Zéno Bianu.

Conocí a fondo el mundo y el funcionamiento de la pequeña edición. La inmensa mayoría de los editores son independientes y se separan drásticamente de la autoedición. Conocí además el universo de la bibliofilia y el trabajo con pintores como Antonio Saura, Anne-Marie Pécheur, Jean Cortot, Julius Baltazar, René Laubies, Michel Mousseau, Lise-Marie Brochen. La vida se desarrolla entre las invitaciones, los encuentros sociales, las lecturas, a veces los cursos, la crítica. El medio cultural francés tiene una estructura opuesta al medio latinoamericano. Hay una gran diversidad y una evolución. Un lector francés está al tanto de lo más reciente y tiene además una cultura clásica. 
No era fácil ir a Chile a partir de 1977. Eran muy pocos entre "los de afuera" los que se aventuraban. El ambiente estaba siempre cargado de amenazas, pero yo encontraba a mis hijos en la misma fecha y así los veía crecer. En 1979 mi padre murió en Chile, pero yo estaba junto a él. A mi regreso murió Caillois. Claude Couffon me propuso traducir y publicar en Gallimard las traducciones de Caillois y otros de mis poemas que haría él mismo. Así se gestó Poema del Sur que apareció en Gallimard, en 1982. Hubo críticas en casi todos los diarios y ha sido reeditado dos veces. La revista Araucaria de los exilados chilenos no lo menciona en su número de ese año consagrado especialmente a la literatura del exilio. Yo no había sido considerado como uno de los que merecían ser protegidos en el exilio aunque presentaba en el público francés una obra de esa importancia. Ocupaba decididamente el lugar de representar a la poesía chilena en Francia. No mencionarme es la manera chilena de ignorarme pensando que ese acto podía afectar mi obra. Eliminar a una persona al no mencionarla es algo que podría ser pretencioso hasta la locura; en realidad es típico de una mentalidad chilena desgraciadamente corriente en los medios literarios; es en realidad una actitud muy coherente en un medio cultural estrecho en que hay muy pocas librerías o casas de edición y todavía menos críticos literarios. Dentro de una isla no ser reconocido es gravísimo. En Francia ese acto es bastante ridículo y así me lo han dicho algunos traductores.

Debo decir para ser justo que este año esa situación, a la que ya me había acostumbrado completamente, ha cambiado. La embajadora Marcia Covarrubias de Marruecos me ha considerado invitado de honor entre el 16 y el 22 de febrero en el salón del libro de Casablanca y en la misma circunstancia he sido invitado por el gobierno de Marruecos.

Desde hace algunos años otra aventura intelectual ha comenzado y debo decir cómo: estaba pintando en mi pieza de 14 metros de la rue des Pyramides, donde cabían, sin embargo, cientos de libros. Suena el teléfono y la secretaria del Ministerio del Exterior me pregunta si puedo cenar con el ministro el viernes. Pensé, por supuesto, que era una broma, pero me dio la dirección del Quai des Orfèvres y fui acompañado por Martínez. Allí me encuentro con que era una invitación seria de Dominique de Villepin. Me encuentro con unos quince invitados: Adonis, Vénus Khoury-Ghata, Jean-Pierre Siméon, Pierre Oster, Jean Métellus, poetas amigos que conocía y caras nuevas. Casi todos teníamos algo en común; éramos de origen extranjero. No nos habían invitado para leer poemas, era una verdadera invitación para comer y conversar. Se me ocurrió entonces que ese tipo de encuentro podía tener una permanencia y un efecto en una obra común. Había una necesidad de escucharse entre nosotros y los poetas franceses. Así nació Confluences poétiques. Dominique de Villepin, al que todavía veo de vez en cuando, apoyó a fondo la idea y pagó de su bolsillo el primer número de la revista. Además, invitó en repetidas ocasiones al grupo creciente de poetas a Matignon.

Una vez más, Francia me demostraba que no era un país como los otros, que había aquí una realidad en la convergencia poética, en esa confluencia que se había producido en la casa del ministro y que luego existía y producía antologías y revistas. Pienso que hay muchas razones para explicar esta situación. Además, no se trataba de un acto protocolar. Me fui a sentar lejos, pero Dominique me llamó para sentarme a su lado y hablar en español. Conocía a fondo la poesía en español. ¿Cómo no sentirse acogido en un país así? Yo sé que los franceses piensan que no son hospitalarios y que hay racismo en Francia, etc. Es necesario saber bien lo que pasa en el mundo para juzgar y valorar la sensibilidad francesa frente al otro, el otro que somos todos.

No he vuelto a publicar libros de poesía en Chile después de los cuadernos que me llevé al exilio, pero publico mis investigaciones sobre el naturalista francés Claudio Gay, que tuvo gran importancia en la creación de la identidad cultural chilena y que hizo el inventario del mundo natural, de vegetales e insectos, y también de la historia política chilena. He tenido la suerte de encontrar y publicar su diario de vida. Vivió entre 1800 y 1873, se sentía un exilado en Chile y heredó la ciencia de otro, este sí un verdadero exilado, el Abate Molina, expulsado de Chile por ser jesuita a fines del siglo XVIII, autor de la primera descripción científica de la naturaleza chilena alabada por Humboldt.

No he hecho cursos regulares en la universidad, pero he sido profesor invitado de la facultad de español de Nancy durante dos años y pude hacer un curso en el Instituto de altos estudios de América Latina. El tema de la indianidad y de los indios me ha interesado siempre y dentro de mi obra lo he tratado en un ensayo. El indio, testimonio de una fascinación, en una antología de la literatura precolombina que he hecho con Zéno Bianu y que hemos publicado en Du Seuil y, sobre todo, con mi novela La muerte del Inca publicada en Francia en la misma editorial, pero también en España, Grecia y Turquía. Vale la pena decir algo sobre esta problemática. 
Se habrán dado cuenta que en la literatura chilena, a diferencia de la literatura peruana o mexicana, hay muy pocos indios. Pere Gimferrer, que publicó mi libro en Seix Barral, me dijo: Vamos a vender pocos libros, a los españoles los indios no les gustan mucho. Los indios son invisibles en Chile. Una frase que se decía siempre en la época en que llegué a Francia era que en Chile no hay indios. Los chilenos decían también otra que puede estimarse complementaria: los chilenos somos los ingleses de América del Sur. Seguramente, por esta razón, ningún gobierno ha nombrado un solo embajador ni alto funcionario de origen indio.

Cuando estuve en Chile, hace unos años, los indios habían invitado a Lagos a una Gran manifestación. Lagos no fue, pero ellos hicieron la fiesta y presentaron sus quejas a un sillón vacío, quizás lo más elocuente es la noticia de que en fecha reciente 40.000 familias indias solicitaban en los tribunales el cambio del apellido para escapar a la discriminación. Desgraciadamente los indios han caído a veces en el exceso de idealizar la raza india, y eso no es admisible de ninguna raza, blanca negra o india. Al terminar esta conferencia vuelvo naturalmente al tema de la indianidad. Dije al comienzo que la indianidad es la cultura básica para todo latinoamericano, aunque sea una cultura herida, escondida u olvidada. Esa represión y ese repudio, puesto que la primera generación de latinoamericanos es, en parte, descendiente de indias repudiadas por los españoles, es el dolor de nuestra literatura. Ese dolor y cántico que se percibe en la literatura profunda de América Latina: en Carpentier, en Rulfo, en Arguedas. Recordemos que el inca Garcilaso de la Vega es una figura ejemplar porque el padre español lo reconoce y lo educa. No fue esa la suerte de la mayoría. 